\title{
Processed Electroencephalogram-Based Monitoring to Guide Sedation in Critically III Patients: A Systematic Review and International Expert Panel-Based Consensus Recommendations
}

Frank A Rasulo ( $\square$ frank.rasulo@gmail.com )

Spedali Civili University Hospital of Brescia, Italy https://orcid.org/0000-0001-8038-569X

Philip Hopkins

University of Leeds Leeds Institute of Biomedical Clinical Sciences

Francisco Almeida Lobo

Cleveland Clinic Abu Dhabi

Pierre Pandin

Centre Universitair Bruxelles Hôpital Erasme: Hopital Erasme

\section{Basil Matta}

Addenbrooke's Hospital Department of Neurology: Cambridge University Hospitals Neurosciences

Carla Carozzi

Istituto Nazionale Neurologico Carlo Besta: Fondazione IRCCS Istituto Neurologico Carlo Besta

\section{Stefano Romagnoli}

AOU Careggi: Azienda Ospedaliero Universitaria Careggi

\section{Anthony Absalom}

Groningen University Medical Center, Holland

\section{Rafael Badenes}

Universitat de Valencia

\section{Thomas Bleck}

NUHS Evanston: Northwestern University Northwestern University Health Service Evanston

\section{Anselmo Caricato}

Policlinico A Gemelli: Policlinico Universitario Agostino Gemelli

\section{Jan Claassen}

Columbia University Irving Medical Center

\section{Andrè Denault}

Montreal Heart Institute: Institut De Cardiologie de Montreal

\section{Cristina Honorato}

Department of anesthesiology and critical care, universidad de navarra

\section{Geert Meyfroidt}

Leuven University Press: Katholieke Universiteit Leuven Universitaire Pers Leuven

\section{Ida Nardiello}

ASST Spedali Civili di Brescia: Azienda Socio Sanitaria Territoriale degli Spedali Civili di Brescia

\section{Finn M Radtke}


Department of Anesthesiology, Nykcøbing F. Hospital Denmark

\section{Zaccaria Ricci}

Pediatric Anesthesia, Meyer University Hospital, Firenze

\section{Chiara Robba}

Department of Anesthesiology, IRCCS San Martino University Hospital, Genova

\section{Fabio S Taccone}

Department of Anesthesiology and Critical Care, Erasmè University Hopital, Brussels

\section{Paul Vespa}

Department of Neurosurgery and Neuro Critical Care, Ronald Reagan Medical Center, UCLA, California

\section{Massimo Lamperti}

Institute of Anesthesiology, Cleveland Clinic Abu Dhabi, UAE

\section{Research}

Keywords: EEG, monitoring, sedation, critically ill, consensus

Posted Date: October 29th, 2021

DOI: https://doi.org/10.21203/rs.3.rs-1014725/v1

License: (c) (i) This work is licensed under a Creative Commons Attribution 4.0 International License. Read Full License 


\section{Abstract}

\section{Background}

The literature related to the use of processed EEG (pEEG) for depth of sedation (DOS) monitoring is increasing, however it is unclear how to use this type of monitoring for critical care patients within the intensive care unit (ICU).

\section{Methods}

We performed a systematic review of the literature according to the Grade of Recommendation assessment, Development, and Evaluation (GRADE) approach. The modified Delphi method was utilised by a team of experts to produce statements and recommendations derived from study questions. Three separate online rounds discussing 89 statements categorized into four domains were formulated. The panelists rated the appropriateness of each statement and were able to suggest modifications or addition of statements. An analysis of anonymised ratings of the statements by part of the panel followed each Delphi round and previously validated criteria were used to define appropriateness and consensus.

\section{Results}

Level of evidence regarding the four domains was very low. Fourteen panelists participated in the Delphi rounds and consensus was reached for 28 out of 89 statements, from which the reccomendations were created. The main findings were that DOS monitoring should be performed in critically ill patients whenever clinical evaluation is not possible, it should be performed by continuous PEEG techniques and the resulting data depicted with graphical tools to facilitate detection of excessive sedation, a potential cause of burst-suppression, and finally, structured training is suggested to achieve a basic pEEG competency.

\section{Conclusions}

Although evidence on using DOS monitors in ICU is scarce and further research is required in order to better define the benefits of using PEEG, the results of this consensus highlight the general agreement that critically-ill patients would benefit from this type of neuromonitoring.

\section{Background}

Liberal sedation protocols and clinical scales are commonly used in the intensive care unit (ICU) for level of consciousness evaluation and management of sedative agents in critically ill patients [1-4]. Moderate to deep sedation (Richmond Agitation Sedation Score [RASS] $\leq-3$ ) may sometimes be necessary in order to avoid discomfort, improve mechanical ventilation tolerance, provide neuroprotection and to avoid awareness, especially when neuromuscular blocking agents are administered [5-7]. Once consciousness is lost, evaluation of depth of sedation (DOS) through clinical scales is no longer possible, exposing the patient to an increased risk of excessive sedation, which has been associated with several complications, such as delirium, prolonged mechanical ventilation, hemodynamic instability, increased length of ICU and hospital stay, hospital mortality, and long-term cognitive sequelae among survivors $[8,9]$. Over the past two decades, several so-called pEEG (processed electroencephalogram) monitoring systems have been introduced into clinical practice to monitor the effects of anesthesia, particularly in the operating room. Such monitoring systems predominantly automatically process EEG recorded from frontal montage (using 2 to 4 channels). However, while pEEG guided monitoring is becoming more 
widely accepted during general anesthesia, its use in critically ill patients for monitoring of sedation is less common, even in patients receiving neuromuscular blocking agents (NMBA) [7].

Therefore, a multidisciplinary panel of experts was convened to develop consensus-based recommendations. The current literature was reviewed to provide evidence-based guidance in response to the identified questions and, in the absence of sufficient clinical data, an experts opinion was solicited. In the absence of consensus, a research agenda was created. Four main topics related to pEEG monitoring in adults admitted to the ICU and requiring sedation were identified:

1- Patient selection: which patients to be monitored with pEEG in the ICU.

2- Techniques for EEG monitoring: focusing on the technical aspects of pEEG monitors, specifically: number of channels required, visualization of a processed or non-processed raw EEG trace, types of parameters most frequently evaluated, (burst suppression, burst suppression ratio, digital subtraction array, adimentional index of sedation/anesthesia, [e.g., bi-spectral index (BIS), patient state index (PSI), state entropy (SE), quantium consciousness index (qCON)], electromyography (EMG) signals), artifact occurrence and identification, duration of monitoring.

3- Use of pEEG monitors: how to use pEEG monitoring devices in the ICU, artifact identification, interaction between different drugs and the raw EEG trace and $\mathrm{pEEG}$ algorithms.

4- Competency to use and teach the principles of pEEG monitoring. discussing the required skills in the analysis of pEEG data, number and types of monitored cases required in order to obtain minimum competency in analyzing this type of neuromonitoring.

\section{Methods}

\section{Panel selection and organization}

The project was conceived by two academic experts in the field of pEEG (ML, FR) who established the project's aims, timeframe and milestones. Following an initial proposal to perform a systematic review of the literature and develop consensus on this topic, 25 clinician experts were invited to participate to the project based on: a- their clinical and/or scientific expertise and involvement in neurocritical care, neuroanesthesiology, neurology and general intensive care practice, $b$ - their willingness to be proactive in the project, $c$ - the presence of some of the experts with potential conflicts of interest that could bias the statements and d- the aim of obtaining an appropriate multidisciplinary representation. A non-voting methodologist $(\mathrm{PH})$ elaborated the relavant documentation for the expert panelists. Clinical queries were developed in the form of six Population/Intervention/Comparison/Outcome (PICO) groups, further leading to the identification of four clinical domains related to the use of pEEG in critically ill patients, which ultimately generated a preliminary list of statements that were submitted to the panelists. All voting members provided a full disclosure of potential conflicts of interest.

\section{Search strategy}

A systematic focused search of the most relevant literature in EMBASE (OvidSP), MEDLINE (OvidSP), Cochrane Central Register, and CINAHL, published from 2000 to Dec 31st 2020, was performed. Observational and experimental studies, including literature and systematic reviews, and meta-analyses, written in English were 
included and made available through Dropbox (https://www.dropbox.com/) to all the panelists. The group of experts was encouraged to add any missing papers of interest and, when felt necessary, to conduct related searches themselves. The full search strategy, including the MeSH terminology, is described in Additional file 1.

All duplicates were removed and the resulting remaining papers retrieved for full-text evaluation. They were then screened and reviewed by two members (IS, ML) for eligibility. Any conflicts regarding the inclusion or the exclusion of articles were resolved through a discussion with a third member (FR). The results of the search strategy are depicted in figure 1 and in the Additional file 1.

\section{Appraisal of the selected studies}

Data were extracted from selected articles using a standardised form. All papers were assessed for the quality of the evidence utilising Grading of Recommendations Assessment, Development and Evaluation (GRADE) methodology (Additional file 3) [10]. Observational studies were defined prior to assessment as having a low quality of evidence [11]. The Risk of bias assessment for included studies is included in Additional file 2. The strength of the recommendation was based on judgement of the level of evidence, and reported as $A$ to $C$. When the literature was insufficient to provide a recommendation, the experts were asked to provide it based on an analysis of the available evidence. Few observational studies with non-comparable outcomes were identified, therefore not permitting us to perform a metanalyses.

\section{Consensus development}

The objective of the Consensus process was to reduce the heterogeneity of different opinions, necessary to reach the highest possible degree of convergence. An initial list of 89 statements was formulated by 4 of the panelists (FR, $\mathrm{ML}, \mathrm{FL}, \mathrm{PP}$ ) and distributed to them prior the first Delphi round in order to provide them with the opportunity to propose any modifications or additional statements. The modified iterative Delphi process was conducted using online tools $[12,13]$. In each round, panel members rated the statements on a 9-point Likert scale with a rating of "1" indicating a completely inappropriate statement through "9" representing a completely appropriate statement. The median rating was used to classify the appropriateness, while the level of consensus was evaluated using the disagreement index (DI), which describes the measure of the spread of ratings with a mathematical adjustment for asymmetry. The questionnaire was submitted to the experts via a web-based survey platform (Google Forms, Menlo Park, California, USA, docs.google.com/forms). After each round, the ratings were collated, summarised and analysed, with the anonymised summary and analysis returned to each panel member before the following round. From round 2 onwards, statements were included within the final, round unless a stopping criterion was reached (DI $<0.5$ or the DI failed to improve by $>15 \%$ in successive rounds). At the completion of the Delphi process, statements were classified as highly appropriate (median rating $\geq 8$ ) or appropriate level of recommendation (LoR) (median rating $\geq 7$ but $<8$ ) and with strong $(\mathrm{DI}<0.5$ ) or weak ( $\mathrm{DI} \geq 0.5$ but $<1)$ consensus respectively.

\section{Results}

Of the 25 experts who were initially invited to join the panel, 21(84\%) agreed and participated. The Delphi process was completed after 3 rounds and the statements defining key terms were used by the panelists to generate consensus definitions for 3 parameters used for ICU DOS. From the formulation of 89 statements, consensus was reached for a total of 28 recommendations pertaining to the 4 main domains previously identified (Table 1). The 
level of evidence was categorized with GRADE whenever possible. An internal review from the panelist and an external review from a non-voting expert (TB) were used to finalise the consensus document.

This document is aimed to be reviewed after a five-year time period, or whenever new evidence from the literature could support the change of an existing recommendation.

\section{Patient selection}

The majority of ICU patients require sedation and previous guidelines [14,15]suggested the routine use of clinical scales in order to monitor sedation. These scales are ordinal scales that can accurately assess consciousness levels during mild to moderate sedation, but they are unreliable when consciousness has been lost. Moreover, scoring involves stimulating the patient which itself alters the level of sedation and patient comfort. We therefore reached consensus and evidence suggesting the use of pEEG when sedation scoring in not possible, such as during deep sedation (RASS -4 or -5) [16]or under neuromuscular blockade. (Table 1 Q1.1)

A correlation between pEEG-based index (e.g. BIS, PSI, SE, qCON) values and the administered dose of intravenous and inhalational anesthetic agents has been demonstrated: the progressive deepening of sedation induces a corresponding progressive reduction in pEEG-based index values [17]. Current data on pEEG monitoring in critically ill patients in ICU are less definitive and more controversial. During neuromuscular blockade, BIS detected oversedation in 18 deeply sedated ICU patients and was shown to highly correlate with the Sedation Agitation Score in 63 mechanically ventilated patients, although the correlation varied among medical, surgical and trauma patients. Similarly, Riker et al. found good correlation between BIS and the SAS but noted that electromyographic interference could affect the accuracy of BIS in cardiac patients receiving neuromuscular blocking agents, a group in whom residual electromyographic activity can cause spurious BIS elevations [18]. Other DOS devices have not yet been evaluated in ICU patients receiving muscle relaxants $[19,20]$. However, it is important to remember that evaluation of brain-stem reflexes and response to pain stimulation remain paramount, since monitoring systems should be used to supplement, and not replace, the clinical examination. Furthermore, they can assist the clinician during the management of TBI [21,22] and to markedly reduce the total dose of sedative used to achieve the same level of clinical sedation [23] (Table 1 Q 1.2)

The ideal timing for initiating DOS monitoring in ICU patients has yet to be investigated, but given the risks of underand over-sedation the experts consider that DOS monitoring should be started as soon as possible when deeper sedation than a RASS of 0 or -1 is required [24]. (Table 1 Q1.3)

Patients admitted to ICU can require multiple interventions (e.g. central line placement, bedside tracheostomy, change of burns dressings, thoracic drainage placement) for which deep sedation, analgesia, and sometimes the administration of neuromuscular blocking agents are required. Several studies have shown an association between pEEG burst suppression and negative outcomes (e.g. delirium, duration of mechanical ventilation and mortality) $[24,25]$. The correlation between duration of over-sedation (in terms of cumulative time spent in BS) and outcome has not yet been studied but BIS has shown clear reliability to detect deep sedation in mechanically ventilated patients [26]. (Table 1 Q1.4)

Patients on ECMO have numerous risk-factors for delirium such as hypoxia, reduced cerebral perfusion and the potential for vascular microemboli. Burst suppression associated with over-sedation might limit the beneficial effect of ECMO on cerebral metabolism and negatively impact patient outcomes [27]. (Table 1 Q1.5) 


\section{Technology}

Processed EEG provides a compressed and simplified view of the raw EEG signals, allowing for potential evaluation by non-neurophysiologists who can alert the neurophysiologists when required because of matters of concern $[28,29]$.Some technical and physiological limitations of these parameters when applied to the bedside for sedation assessment should be considered: pEEG monitoring to guide sedation of patients in intensive care is not able to distinguish specific signatures of each drug used for sedation [30-32]. It requires specific knowledge to recognize the features and changes in pEEG values associated with sedation with ketamine, nitrous oxide (faster EEG oscillations, higher index values) and dexmedetomidine (profound slow oscillations, low index values in an awakable patient) [32]. Nonetheless integration of pEEG parameters in a wide monitoring platform in addition to the raw EEG can facilitate accurate control of sedation level and differentiate between sedation and sleep [33-35]. (Table 1 Q2. 1)

Spectral Edge Frequency (SEF95) was shown to correlate with the level of sedation. In critically ill patients sedated with midazolam and morphine SEF95 was modestly able to detect deep sedation levels (area under the receiver operating characteristic curve, AUC 0.687) but was a better predictor of light sedation states (AUC 0.798) [36].Overall SEF has limitated value when used to titrate sedative administration. It is not influenced by drug-specific EEG changes, and may show paradoxical changes when ketamine, nitrous oxide, dexmedetomidine or a combination of drugs is used, or in the elderly or very sick patients with a low baseline voltage. As it is a summary statistic major changes in the frequency power spectrum may occur without a significant change in SEF. (Table 1 Q2.2)

Processed EEG monitors were launched primarily as 'hypnosis monitors' during surgery [37-39].The use of the output index ranges suggested by the manufacturer for light and deep sedation might be an effective tool as a first approach to guide and individualize sedative drug dosing schemes integrated in a multimodal monitoring strategy in critically ill patients $[40,41]$. Some limitations of this technology are represented by the influence of EMG/artifacts and patient conditions (e.g. brain damage) since they can alter the pEEG number [39,41-44]. Therefore, the pEEG number should be verified by the concordance with the raw EEG rhythm [45,46]. (Table 1 Q2.3)

It may be challenging for clinicians to interpret a sedation state from the unprocessed electroencephalogram in realtime. The presence of a spectrogram makes it easier to interpret the subtle changes across the range of EEG frequencies. Furthermore, by presenting longer time frames than raw EEG, slower variations occurring over time are more likely to be identified. Different sedatives, acting on different neuronal circuits by different mechanisms, have distinct EEG signatures which produce different spectrogram patterns. Propofol-induced unconsciousness for example is associated with slow-delta and alpha oscillations [47].EEG spectral patterns in ICU patients have a standardized nomenclature with high inter-rater agreement and can be a useful tool for EEG screening [48].Age and co-morbidities decrease the EEG amplitude, and weaker power in the alpha band increases the propensity for burst suppression which is a phenotype of a vulnerable, frail brain [46]. The possibility to adjust the power scale of the spectrogram increases utility as it can increase the visibility of such "weak" bandwidths. (Table 1 Q2.4)

BS has been associated with a higher risk of delirium and mortality in critically ill patients $[48,49]$. It is important to distinguish unintended BS resulting from overdosing of sedative drugs, from therapeutic induced BS which might be potentially useful in situations of low cerebral blood flow and altered metabolism such as refractory intracranial hypertension and the treatment of refractory status epilepticus. Despite a lack of clear evidence to support this practice and large variability in the degree of EEG suppression achieved, BS remains incorporated in many pragmatic refractory status epilepticus treatmeant algorithms [50-54]. (Table 1 Q2.5) 


\section{Assessment of sedation}

Besides the differences in pharmacodynamics and pharmacogenetics in relation to anaesthetic and sedative drugs, other factors may influence the EEG signal: cerebral blood flow, hypothermia, age, brain damage and others. When interpreting the $\mathrm{pEEG}$, all possible causes of patient variability must be taken into consideration including different EEG spectra during burst and suppression periods [32,65]. (Table 1 Q3.1)

Although pEEG has the advantage of being easily interpreted by doctors and nurses who are not experts in neurophysiology, it is very vulnerable to artefacts caused electromyographic signals from shivering or facial movements or from interference from electrical signals from nearby machines (body thermoregulating systems, haemofiltration and ECMO machines) [56]. Efforts to improve artefact detection and removal and signal-to-noise ratios are underway [57-61]. Until these systems have been validated, subjective sedation scoring systems should be considered more reproducible than pEEG for patients who are lightly sedated and for whom neurological evaluation is possible, particularly when the risks of artefact exposure are high [62,63]. (Table 1 Q3.2)

Processed EEG devices generally appear best suited for sedative titration during deep sedation or in patients who have received neuromuscular blockade, although observational data suggest potential benefit with lighter sedation as well [64]. In non-paralyzed patients, electromyographic signals may impair the utility of the displayed index value [65]. (Table 1 Q3.3)

Processed EEG devices cannot, and should not replace the clinical validated scales but rather be supplemental to them, since these later are globally more informative of the clinical sedation status of ICU patients. (Table 1 Q3.4)

EEG-based monitoring devices are well suited to facilitate sedative titration during deep sedation and especially when neuromuscular blocking agents have been administered (eg. in patients with ARDS, those requiring prone positioning, venous-arterial and venous-venous ECMO). [27]. (Table 1 Q3.5)

\section{Competences, Training and Support}

The use and recourse to technologies, upon which clinicians increasingly rely on, requires adequate and appropriate training [66,67]. (Table 1 Q4.1)

Initially, clinicians require knowledge and experience in order to apprehend the principle of pEEG monitoring and to interpret the basic EEG waveforms, spectrogram and processed indices during sedation in the healthy brain and with minimal interference, for which a 30-min training session is considered sufficient [68]. This is followed by a further period of training and experience to understand the influence of other pathologies/conditions/artifacts on the $p E E G$ index [68]. Finally, clinicians should be tautght to be aware of the limits and advantages of each pEEG monitor used. Frequent use of pEEG in within the ICU, combined with multidisciplinary teaching, is warranted to improve the performance of clinicians when using pEEG monitoring to manage patients and estimate their prognosis. (Table 1 Q4.2)

In recent years, experience has been gained in anaesthesia and intensive care medicine regarding the teaching of ultrasound-based techniques in relatively short periods of time (days to weeks). The use ofinteractive teaching approaches and simulation seem to be very effective [70-74]. 
Bombardieri and colleagues reported the application of simulation for training in $\mathrm{pEEG}$ and found a significant improvement in clinicians without prior EEG training in identifying EEG waveforms corresponding to different hypnotic depths and also in recognizing when the hypnotic depth suggested by the EEG was discordant with the pEEG index [75] (Table 1 Q4.3).

The participation of neurospecialists in the faculty of pEEG teaching and training courses provides effectiveness and quality in two respects: firstly, because of their gained knowledge of the EEG signal itself in all its aspects (basic and theoretical, physiological and pathophysiological, neurological and pharmacological) and secondly, their more advanced experience regarding EEG training [71-74,76].

Literature is divided in regards to the balance between support and continuing education, and regular recertification [70]. It is also not clear which authority should be responsible for certification: academic, regional or even national level, professional or scientific society [72].

The quality of the practice of using any technology to improve patient care and outcomes must be guaranteed. Telemedicine-based solutions have been used with growing effectiveness in high as well as low- and middleincome countries. How this is implemented will depend on local circumstances $[70,71]$.

A graphical representation (trend vs. spectrogram) represents a third reading level of the EEG that should be implemented and simultaneously visible with the raw trace and other derived parameters such as pEEG index, SR and MEF/SEF. Graphical representations convey information about the effect of general anaesthesia or sedation, the spectral signature of the drug, and patterns associated with age of the patient [71-74]. Trends or spectrograms can reveal the occurrence of excessive EEG suppression, or an increase in activity level consistent with a nonconvulsive seizure episode, both of which as amenable to rapid therapeutic intervention, and specific patterns may help the clinician to assess the patient's underlying condition and formulate a prognosis (i.e. delta/theta septic encephalopathy, renal or hepatic failure, BS due to severe brain damage) [76-79]. (Table 1 Q 4.4-9)

\section{Agenda for future research}

Depth of sedation monitoring of critically ill patients remains a challenging topic due to the contradicting results in the literature [80]. The main barriers to the routine use of these monitors in ICU are represented by: 1) the lack of knowledge, especially outside the neurological ICU, 2) the lack of validation of the use of the monitors for prolonged sedation, 3) the lack of a standardization between monitors based on different EEG analysis algorithms, 4) the financial constraints limiting availability of the monitors and finally, and 5) the unknown effect of excessive sedation on the long-term outcome of these patients although it has been demonstrated that a prolonged duration with (bilateral) BIS 0 values serves as a better outcome predictor after OHCA as compared to a single observation [81]. In fact, their use may become necessary in order to understand if delirium or cognitive impairments after ICU are related to oversedation or other EEG abnormalities.

Processed EEG could be a useful tool to predict outcome as BIS values are correlated with the prognosis of patients with coma in ICU, and can be a useful marker for estimating the prognosis of comatose patients [82] including when they are witdrawm from sedation [83].

This consensus suggests that the time has come to implement DOS monitoring with pEEG monitors in sedated critically-ill patients especially in those deeply sedated and/or receiving neuromuscular blocking agents. Artifacts from electrical interference from other machines, from patient movement or concomitant neurological diseases can 
reduce the utility of this monitoring. We therefore suggest that PEEG index values should always be interpreted in the context of the other available quantitative EEG parameters (such SEF and SR), and to assess the raw EEG trace, the density spectral array and the clinical status of the patient.

\section{Limitations}

A potential limitation of the current consensus is represented by the participants' conflict of interests, involved with some of the DOS monitors manufacturers, which may have biased their votes to the statements. This is debatable since experts in a specific field are frequently asked for their advice regarding new technologies.

Another limitation is related to the lack of observational studies when DOS monitoring was applied in the ICU. DOS monitoring was first implemented by anesthesiologists for intra-operative monitoring to avoid awareness. With time, the technology gradually made its way into critical care to be used for patients who require prolonged and deep sedation, with or without muscle relaxants. Since the controversies on this topic constituted the trigger for the current project, we made sure to include all different opinions which arised within the group. The lack of consensus on certain statements, particularly in sections 3 and 4, confirmed the broad spectrum of opinions addressed during the Delphi process, thereby highlighting its value.

\section{Conclusions}

General intensivist should acquire the knowledge and competencies to titrate sedative drugs to avoid over and undersedation. Compentences, training and support to interpret this type of monitoring represent three inseparable pillars of a technology likely to become indispensable in the medical practice. However, the quality their use is directly determined by knowledge of the physiology and/or pathophysiology of the signals on which they are based. This knowledge is not currently an integral part of the general knowledge of intensivists, creating a barrier regarding the use of this innovative technology which can only be overcome by training and education. Regular training in pEEG assessment and the availability of support should be available. What remains to be determined is who will be responsible for implementation (universities and training masters, professional and learned societies, etc.). Finally, the methodical and continuous analysis of the efficiency and pedagogical effectiveness of such teaching and support represents an issue that has yet to be implemented and which certainly predicates the future of these practices.

\section{Abbreviations}

1. Depth of sedation monitoring (DOS)

2. Intensive care unit (ICU)

3. Processed electroencephalography ( $\mathrm{EEEG)}$

4. Richmond Agitation Sedation Score (RASS)

5. Bi-spectral index (BIS)

6. Patient state index (PSI)

7. State entropy (SE)

8. Quantium consciousness index (qCON)

9. Electromyography (EMG)

10. Population/Intervention/Comparison/Outcome (PICO) 
11. Grading of Recommendations Assessment, Development and Evaluation (GRADE)

12. Disagreement index (DI)

13. Level of recommendation (LoR)

14. Extracorporeal membrane oxygenation (ECMO)

15. Area under the receiver operating characteristic curve (AUC)

Definitions of most frequently used terminology are listed in Additional file 4.

\section{Declarations}

\section{Acknowledgements}

None

\section{Authors' contributions}

FAR, ML contributed to the conception and design of this study. FAR, ML, FAL, PP, BM, CC, SR, AA, RB, AC, JC, AD, CH, GM, IN, FMR, ZR, CR, FST and PV took place in the Delphi process.

FAR, PH, ML, FAL, PP, BM, CC and SR contributed to the acquisition of data. PH analyzed and interpreted the data. FAR, PH, ML, FAL, PP, BM, CC and SR drafted the manuscript. TB contributed to its critical revision. Both FAR and $M L$ approved the final version submitted for publication and take responsibility for the statements made in the published article. All authors read and approved the final manuscript.

\section{Funding}

None

\section{Availability of data and materials}

All data generated or analyzed during this study are included in this published article and its supplementary information files.

\section{Consent for publication}

Not applicable.

\section{Competing interests}

The authors declare no competing interests with the contents of this research

\section{Financial Disclosure and Conflicts of Interest:}

The following authors:

BM - receives lecture fees and Senior Medical Director for Masimo International 
FT - receives lecture fees for Masimo International and Nihon Khoden

FR - receives lecture fees for Masimo International

$A D$ - speaker bureau for Masimo International, Equipment Grant for Edwards

SR - receives lecture fees for Masimo International, Medtronic, Edwards

PV - Consultant for Ceribell, UCB Pharma

RB - receives lecture fees for Masimo International, Medtronic

JC - received Grants for NINDS, NIH, McDonnel Foundation, CE Neurosystems minority shareholder

FMR - receives lecture fees for Medtronic

FL - receives lecture fees for Masimo International

$\mathrm{ML}$ - receives lecture fees for Masimo International, Medtronic, Edwards

The remaining authors:

GM, CR, CC, IN, AC, ZR, CH, AA, PP, TB, PH have disclosed that they do not have Conflicts of Interest related to topics treated in this consensus.

\section{References}

1. Coursin DB, Skrobik Y: What Is Safe Sedation in the ICU? N Engl J Med. 2019;380:2577-2578.

2. Hughes CG, McGrane S, Pandharipande PP: Sedation in the intensive care setting. Clin Pharmacol. 2012;4:5363.

3. Kress JP, Pohlman AS, O'Connor MF, Hall JB: Daily interruption of sedative infusions in critically ill patients undergoing mechanical ventilation. N Engl J Med. 2000;342:1471-7.

4. Jacobi J, Fraser GL, Coursin DB et al: Clinical practice guidelines for the sustained use of sedatives and analgesics in the critically ill adult. Crit Care Med. 2002;30:119-41.

5. Penglin $M$, Jingtao L, Xiuming $X$ et al: Practice of sedation and the perception of discomfort during mechanical ventilation in Chinese intensive care units. J Crit Care. 2010;25:451-457.

6. Oddo M, Crippa IA, Mehta S, et al: Optimizing sedation in patients with acute brain injury. Crit Care. 2016;20:128.

7. Chanques G, Constntin J, Devlin J et al: Analgesia and sedation in patients with ARDS. Intensive Care Med 2020. 46:2342-2356.

8. Reade MC, Finfer S: Sedation and Delirium in the Intensive Care Unit. N Engl J Med. 2014;370:444-454.

9. Ouimet S, Kavanagh BP, Gottfried SB, SkrobikI Y: Incidence, risk factors and consequences of ICU delirium. Intensive Care Med. 2014;33:66-73.

10. Guyatt G, Oxman AD, Akl EA, et al. GRADE guidelines: 1. Introduction-GRADE evidence profiles and summary of findings tables. J Clin Epidemiol. 2011;64:383-94.

11. Guyatt GH, Oxman AD, Vist G, et al. GRADE guidelines: 4. Rating the quality of evidence-study limitations (risk of bias). J Clin Epidemiol. 2011;64:407-15.

Page $12 / 22$ 
12. Hopkins PM, Cooke PJ, Clarke RC, et al: Consensus clinical scoring for suspected perioperative immediate hypersensitivity reactions. Br J Anaesth. 2019;123:e29-e37.

13. Fitch K, Bernstein SJ, Aguilar MD, Burnand B, LaCalle JR, et al. The RAND/UCLA Appropriateness Method User's Manual, Santa Monica, Calif.: RAND Corporation, MR-1269-DG-XII/RE,200.2021: https://www.rand.org/pubs/monograph_reports/MR1269.html.

14. DAS-Taskforce 2015, Baron R, Binder A et al: Evidence and consensus-based guideline for the management of delirium, analgesia, and sedation in intensive care medicine. Revision 2015 (DAS-Guideline 2015) - short version. Ger Med Sci;13:19.

15. Surveillance of delirium: prevention, diagnosis and management (NICE guideline CG103). https://www.nice.org.uk/guidance/cg103/resources/2018-surveillance-on delirium-prevention-diagnosis-andmanagement-nice-guideline-cg103-pdf-8546233843141.

16. Karamchandani K, Rewari V, Trikha A, Batra RK. Bispectral index correlates well with Richmond agitation sedation scale in mechanically ventilated critically ill patients. J Anesth. 2010;24(3):394-398.

17. Johansen JW, Sebel PS: Development and clinical application of electroencephalographic bispectrum monitoring. Anesthesiology. 2000;93:1336-44.

18. Riker RR, Fraser GL, Simmons LE, et al: Validating the Sedation-Agitation Scale with the Bispectral Index and Visual Analog Scale in adult ICU patients after cardiac surgery. Intensive Care Med. 2001;27:853-8.

19. Vivien B, Di Maria S, Ouattara A, et al: Overestimation of Bispectral Index in sedated intensive care unit patients revealed by administration of muscle relaxant. Anesthesiology. 2003;99:9-17.

20. Schneider G, Heglmeier S, Schneider J, Tempel G, Kochs EF. Patient State Index (PSI) measures depth of sedation in intensive care patients. Intensive Care Med. 2004;30(2):213-216.

21. Yan K, Pang L, Gao H, et al: The Influence of Sedation Level Guided by Bispectral Index on Therapeutic Effects for Patients with Severe Traumatic Brain Injury. World Neurosurg. 2018;110:e671-e683.

22. Deogaonkar A, Gupta R, DeGeorgia M, et al. Bispectral Index monitoring correlates with sedation scales in braininjured patients. Crit Care Med. 2004;32:2403-2406.

23. Olson DM, Thoyre SM, Peterson ED, Graffagnino C. A randomized evaluation of bispectral index-augmented sedation assessment in neurological patients. Neurocrit Care. 2009;11:20-27.

24. Andresen JM, Girard TD, Pandharipande PP et al. Burst Suppression on Processed Electroencephalography as a Predictor of Post-Coma Delirium in Mechanically Ventilated ICU Patients. Crit Care Med. 2014;3:3171-3177.

25. Watson PL, Shintani AK, Tyson R et al: Presence of electroencephalogram burst suppression in sedated, critically ill patients is associated with increased mortality. Crit Care Med. 2008;36:3171-7.

26. Wang ZH, Chen H, Yang YL, et al. Bispectral Index Can Reliably Detect Deep Sedation in Mechanically Ventilated Patients: A Prospective Multicenter Validation Study. Anesth Analg. 2017;125:176-183.

27. deBacker J, Tamberg E, Munshi L, et al:. Sedation Practice in Extracorporeal Membrane Oxygenation-Treated Patients with Acute Respiratory Distress Syndrome: A Retrospective Study. ASAIO J. 2018;64:544-551.

28. Tonner $\mathrm{PH}$, Bein B: Classic electroencephalographic parameters: median frequency, spectral edge frequency, etc. Best Pract Res Clin Anesthesiol. 2006;20:147-159.

29. Swisher CB, Sinha SR: Utilization of quantitative EEG trends for critical care continuous EEG monitoring: a survey of neurophysiologists. J Clin Neurophysiol. 2016;33:538-544.

30. Pandit JJ, Russel IF, Wang M: Interpretations of responses using the isolated forearm technique in general anesthesia: a debate. Br J Anaesth. 2015;115:i32-i45. 
31. Sanders RD, Tononi G, Laureys S, et al: Unresponsiveness $¥$ Unconsciousness. Anesthesiology. 2012;116:94659.

32. Purdon PL, Sampson A, Pavone K, et al: Clinical Electroencephalography for anesthesiologists: Part I: Background and basic signatures. Anesthesiology. 2015;123:937-960.

33. Escallier KE, Nadelson MR, Zhou D, et al: Monitoring the brain: processed electroencephalogram and perioperative outcomes. Anaesthesia. 2014;69:899-910.

34. Drohan CM, Cardi Al, Rittenberger JC, et al: Effect of sedation on quantitative electroencephalography after cardiac arrest. Resuscitation. 2018; 124:132-137.

35. Vacas S, McInrue E, Gropper MA, et al. The Feasibility and Utility of Continuous Sleep Monitoring in Critically III Patients Using a Portable Electroencephalography Monitor. Anesth Analg. 2016;123:206-212.

36. Roustan JP, Valette S, Aubas P, Rondouin G, Capdevila X. Can electroencephalographic analysis be used to determine sedation levels in critically ill patients?. Anesth Analg. 2005;101:1141-1151.

37. Bruhn J, Myles PS, Sneyd R, et al: Depth of anaesthesia monitoring: what's available, what's validated and what's next? Br J Anaesth. 2006;97:85-94.

38. Lobo FA, Schraag S: Limitations of anaesthesia depth monitoring. Curr Opin Anaesthesiol. 2011;24:657-664.

39. Dahaba AA: Different conditions that could result in the bispectral index indicating an incorrect hypnotic state. Anesth Analg. 2005;101:765-73.

40. Vacas S, Cannesson M: Noninvasive monitoring and potential for patient outcome. J Cardiothorac Vasc Anesth. 2019;33:S76-S83.

41. Montupil J, Defresne A, Bonhomme V: The raw and processed electroencephalogram as a monitoring and diagnostic tool. J Cardiothorac Vasc Anesth. 2019;33:S3-S10.

42. Walsh TS, Ramsay P, Lapinlampi TP, Särkelä MO, Viertiö-Oja HE, Meriläinen PT. An assessment of the validity of spectral entropy as a measure of sedation state in mechanically ventilated critically ill patients. Intensive Care Med. 2008;34:308-315.

43. Sackey PV, Radell PJ, Granath F, Martling CR. Bispectral index as a predictor of sedation depth during isoflurane or midazolam sedation in ICU patients. Anaesth Intensive Care. 2007;35:348-356.

44. Vivien B, Di Maria S, Ouattara A, Langeron O, Coriat P, Riou B. Overestimation of Bispectral Index in sedated intensive care unit patients revealed by administration of muscle relaxant. Anesthesiology. 2003;99:9-17.

45. Bennet C, Voss LJ, Barnard JP et al: Practical use of the raw electroencephalogram waveform during general anesthesia: the art and science. Anesth Analg. 2009;109:539-50.

46. Fahy BG, Chau DF: The technology of processed electroencephalogram monitoring devices for assessment of depth of anesthesia. Anesth Analg. 2018;126:111-117.

47. Purdon PL, Pierce ET, Mukamel EA, et al: Electroencephalography signatures of loss and recovery of consciousness from propofol. Proc Natl Acad Sci. 2013;110:E1142-5.

48. Zafar SF, Amorim E, Williamsom CA, et al: A standardized nomenclature for spectrogram EEG patterns: Interrater agreement and correspondence with common intensive care unit EEG patterns. Clin Neurophysiol. 2020;131:2298-2306.

49. Ching S, Purdon PL, Vijayan S: A neurophysiological-metabolic model for burst suppression PNAS. 2012;109:3095-3100.

50. Soehle M, Dittmann A, Ellerkmann RK, et al: Intraoperative burst suppression is associated with postoperative delirium following cardiac surgery: a prospective, observational study. BMC Anesthesiol. 2015;15:61. 
51. Johnson EL, Martinez NC, Ritzl E: EEG characteristics of successful burst suppression for refractory status epilepticus. Neurocrit Care. 2016;25:407-414.

52. Phabphal K, Chisurajinda S, Somboon T, et al: Does Burst Suppression achieve seizure control in refractory status epilepticus? BMC Neurol. 2018;18:46.

53. Kang BS, Jung KH, Shin JW, Moon JS et al: Induction of burst suppression or coma using intravenous anesthetics in refractory status epilepticus. J Clin Neurosci. 2015;22:854-858.

54. An J, Jonnalagadda, Junior VM, Purdon PL et al : Variability in pharmacologically-induced coma for treatment of refractory status epilepticus. PloS One. 2018;13:e0205789.

55. Prisco L, Ganau M, Aurangzeb S, et al: A pragmatic approach to intravenous anaesthetics and electroencephalographic endpoints for the treatment of refractory and super-refractory status epilepticus in critical care. Seizure. 2020;75:153-164.

56. Sundt TM, Sharbrough FW, Piepgras DG, et al: Correlation of cerebral blood flow and electroencephalographic changes during carotid endarterectomy with results of surgery and hemodynamics of cerebral ischemia. Mayo Clin Proc. 1981; 56:533-43.

57. Hajat Z, Ahmad N, Andrzejowsk J: The role and limitations of EEG -based depth of anaesthesia monitoring in theatres and intensive care. Anaesthesia. 2017;72:38-47.

58. Zhou DW, Westover MB, McClain LM, et al. Clustering analysis to identify distinct spectral components of encephalogram burst suppression in critically ill patients. Annu Int Conf IEEE Eng Med Biol Soc. 2015;2015:7258-726.

59. White DM, Van Cott AC: EEG artifacts in the intensive care unit setting. Am J Electroneurodiagnostic Technol. 2010;50:8-25.

60. Young B, Osvath L, Jones D: A Novel EEG Artifact in the Intensive Care Unit. J Clin Neurophysiology. 2002;19:484-486.

61. Urigüen JA, Garcia-Zapirain B: EEG artifact removal-state-of-the-art and guidelines. J Neural Eng. 2015;12:031001.

62. Tandle A, Nandini J, Pancham D et al: Classification of Artefacts in EEG Signal Recordings and EOG Artefact Removal using EOG Subtraction. Communications on Applied Electronics. 2016;6: 2394-4714.

63. Herman ST, Abend NS, Bleck TP et al: Consensus Statement on Continuous EEG in Critically III Adults and Children, Part II: Personnel, Technical Specifications, and Clinical Practice. J Clin Neurophysiol. 2015;32:96108.

64. Sessler CN, Grap MJ, Ramsay MA: Evaluating and monitoring analgesia and sedation in the intensive care unit. Crit Care. 2008;12.3:S2.

65. Arbour R, Waterhouse J, Seckel MA: Correlation between the Sedation-Agitation Scale and the Bispectral Index in ventilated patients in the intensive care unit. Heart Lung. 2009;38:4336-345.

66. Devlin JW, Skrobik Y, Gèlinas S et al : Clinical Practice Guidelines for the Prevention and Management of Pain, Agitation/Sedation, Delirium, Immobility, and Sleep Disruption in Adult Patients in the ICU. Crit Care Med. 2018;46: e825-e873.

67. Kubota Y, Nakamoto H, Egawa S, Kawamata T. Continuous EEG monitoring in ICU. J Intensive Care. 2018;6:39.

68. Haider HA, Esteller R, Hahn CD, et al: Critical Care EEG Monitoring Research Consortium. Sensitivity of quantitative EEG for seizure identification in the intensive care unit. Neurology. 2016;30;87:935-44. 
69. Goenka A, Boro A, Yozawitz E: Comparative sensitivity of quantitative EEG (QEEG) spectrograms for detecting seizure subtypes. Seizure. ;201855:70-75.

70. Zafar SF, Amorim E, Williamsom CA, et al: A standardized nomenclature for spectrogram EEG patterns: Interrater agreement and correspondence with common intensive care unit EEG patterns. Clin Neurophysiol. 1993;131:2298-2306.

71. Juan E, KaplanPW, Oddo M et al: EEG as an Indicator of Cerebral Functioning in Postanoxic Coma. J Clin Neurophysiol. 2015;32:465-71.

72. Hanley D, Prichep LS, Badjatia N, et al: A Brain Electrical Activity Electroencephalographic-Based Biomarker of Functional Impairment in Traumatic Brain Injury: A Multi-Site Validation Trial. J Neurotrauma. 2018;35:41-47.

73. Perucca P, Smith G, Santana-Gomez C, et al: Electrophysiological biomarkers of epileptogenicity after traumatic brain injury. Neurobiol Dis. 2019;123:69-74.

74. Wiley SL, Razavi B, Krishnamohan P, et al: Quantitative EEG Metrics Differ Between Outcome Groups and Change Over the First $72 \mathrm{~h}$ in Comatose Cardiac Arrest Patients. Neurocrit Care. 2018;28:51-59.

75. Bombardieri AM, Wildes TS, Stevens T, et al: Practical Training of Anesthesia Clinicians in Electroencephalogram-Based Determination of Hypnotic Depth of General Anesthesia. Anesth Analg. 2020;130:777-786.

76. Zubler F, Koenig C, Steimer A, et al: Prognostic and diagnostic value of EEG signal coupling measures in coma. Clin Neurophysiol. 2016;127:2942-2952.

77. Touchard C, Cartailler J, Levé C, et al: EEG Power Spectral Density under Propofol and Its Association with Burst Suppression, a Marker of Cerebral Fragility. Clinical Neurophysiology. 2019;130:1311-1319.

78. Shao YR, Kahali P, Houle TT, et al. Low Frontal Alpha Power Is Associated With the Propensity for Burst Suppression: An Electroencephalogram Phenotype for a "Vulnerable Brain". Anesth Analg. 2020;131:1529-1539.

79. Koch S, Feinkohl I, Chakravarty S. Cognitive impairment is associated with absolute intraoperative frontal alpha-band power but not with baseline alpha-band power: a pilot study. BioCog Study Group. Dement Geriatr Cogn Disord. 2019;48:83-92.

80. Shetty RM, Bellini A, Wijayatilake DS, Hamilton MA et al: BIS monitoring versus clinical assessment for sedation in mechanically ventilated adults in the intensive care unit and its impact on clinical outcomes and resource utilization. Cochrane Database Syst Rev. 2018;2:CD011240.

81. Eertmans, W., Genbrugge, C., Haesevoets, G. et al. Recorded time periods of bispectral index values equal to zero predict neurological outcome after out-of-hospital cardiac arrest. Crit Care. 2017;21:22.

82. Dou L, Gao HM, Lu L, Chang WX. Bispectral index in predicting the prognosis of patients with coma in intensive care unit. World J Emerg Med. 2014;5:53-56.

83. Neus Fàbregas, Pedro L. Gambús, Ricard Valero, Enrique J. Carrero, Lydia Salvador, Elysabeth Zavala, Enrique Ferrer; Can Bispectral Index Monitoring Predict Recovery of Consciousness in Patients with Severe Brain Injury? Anesthesiology. 2004;101:43-51.

\section{Tables}

Table 1. List of Domains and Statement/Recommendation, and their corresponding Level of Consensus, Level of Evidence and Strength of Recommendation, resulting from the Delphi process. 


\begin{tabular}{|c|c|c|c|c|}
\hline Domain & Statement/Recommendation & Level of Consensus & $\begin{array}{l}\text { Level of } \\
\text { Evidence }\end{array}$ & $\begin{array}{l}\text { Strength of } \\
\text { Recommendation }\end{array}$ \\
\hline \multicolumn{5}{|l|}{$\begin{array}{l}\text { 1. Patient } \\
\text { selection }\end{array}$} \\
\hline \multirow[t]{2}{*}{$\begin{array}{l}\text { Q.1.1 Should all } \\
\text { patients receiving } \\
\text { sedation in ICU be } \\
\text { monitored with } \\
\text { depth of sedation } \\
\text { monitors? }\end{array}$} & $\begin{array}{l}\text { We recommend that all } \\
\text { patients receiving sedation } \\
\text { in ICU should be monitored } \\
\text { with depth of sedation } \\
\text { monitors, if clinical } \\
\text { evaluation is not possible }\end{array}$ & $\begin{array}{l}\text { Highly } \\
\text { appropriate/strong }\end{array}$ & $2 b^{(19)}$ & B \\
\hline & $\begin{array}{l}\text { We recommend that any } \\
\text { patient for whom deep } \\
\text { sedation (RASS - } 3 \text { or less) is } \\
\text { required will benefit from } \\
\text { depth of sedation monitoring }\end{array}$ & $\begin{array}{l}\text { Highly } \\
\text { appropriate/strong }\end{array}$ & $2 b^{(23,24)}$ & B \\
\hline $\begin{array}{l}\text { Q.1.2 Should } \\
\text { patients receiving } \\
\text { sedation in ICU be } \\
\text { monitored with } \\
\text { depth of sedation } \\
\text { monitors only } \\
\text { when they are } \\
\text { mechanically } \\
\text { ventilated? }\end{array}$ & $\begin{array}{l}\text { Patients receiving sedation } \\
\text { in ICU should be monitored } \\
\text { with depth of sedation } \\
\text { monitors only if } \\
\text { neuromuscular blockade is } \\
\text { used for meechanical } \\
\text { ventilation. Statement not } \\
\text { recommended }\end{array}$ & Inappropriate/Strong & $\begin{array}{l}2 b \\
(21,22,24,25)\end{array}$ & B \\
\hline $\begin{array}{l}\text { Q } 1.3 \text { When } \\
\text { should depth of } \\
\text { sedation } \\
\text { monitoring be } \\
\text { started in ICU } \\
\text { patients? }\end{array}$ & $\begin{array}{l}\text { We recommend that depth of } \\
\text { sedation monitoring should } \\
\text { be used continuously } \\
\text { starting as soon as possible } \\
\text { after ICU admission } \\
\text { whenever indicated. }\end{array}$ & $\begin{array}{l}\text { Highly } \\
\text { appropriate/strong }\end{array}$ & $2 a^{(29)}$ & B \\
\hline $\begin{array}{l}\text { Q } 1.4 \text { Should } \\
\text { depth of sedation } \\
\text { be monitored in } \\
\text { patients receiving } \\
\text { short-term deep } \\
\text { sedation for } \\
\text { procedures } \\
\text { performed in ICU? }\end{array}$ & $\begin{array}{l}\text { We recommend that patients } \\
\text { receiving short-term deep } \\
\text { sedation for procedures } \\
\text { performed in ICU require } \\
\text { depth of sedation } \\
\text { monitoring. }\end{array}$ & Appropriate/strong & $2 b^{(29-31)}$ & B \\
\hline $\begin{array}{l}\text { Q } 1.5 \text { Should } \\
\text { patients on Veno- } \\
\text { venous } \\
\text { Extracorporeal } \\
\text { Membrane } \\
\text { Oxygenation } \\
\text { (ECMO) or } \\
\text { ExtraCorporeal } \\
\text { Life Support } \\
\text { (ECLS)/Veno- } \\
\text { Arterial ECMO } \\
\text { require depth of } \\
\text { sedation } \\
\text { monitoring? }\end{array}$ & $\begin{array}{l}\text { We recommend that depth of } \\
\text { sedation monitoring should } \\
\text { be used for patients } \\
\text { receiving ECMO. }\end{array}$ & $\begin{array}{l}\text { Highly } \\
\text { appropriate/strong }\end{array}$ & $2 b^{(32)}$ & B \\
\hline \multicolumn{5}{|l|}{$\begin{array}{l}\text { 2. Technological } \\
\text { aspects }\end{array}$} \\
\hline $\begin{array}{l}\text { Q } 2.1 \text { Is processed } \\
\text { quantitative EEG }\end{array}$ & $\begin{array}{l}\text { We recommend that } \\
\text { processed quantitative EEG }\end{array}$ & $\begin{array}{l}\text { Highly } \\
\text { appropriate/strong }\end{array}$ & $\mathrm{N} / \mathrm{A}$ & C \\
\hline
\end{tabular}


adequate to monitor the level of sedation? is adequate to monitor the level of sedation

\section{Q 2.2 Is Spectral Edge Frequency an adequate parameter to monitor the level of sedation in ICU patients?}

\section{Q 2.3 Are} dimensionless numerical scales of alertness adequate to monitor the level of sedation?

\section{Q 2.4 Is it} meaningful to have a continuous coloured density spectrogram of the EEG?

\section{Q 2.5 Should Burst Suppression (BS) be avoided in all circumstances?}

We suggest that Spectral Edge Frequency (SEF) is an adequate method to monitor the level of sedation.
Appropriate/strong

$2 a^{(41,43)}$

B

\section{We suggest that If using dimensionless numerical scales of alertness, the manufacturer target intervals for light or deep sedation should be used as clinically indicated.}

Appropriate/strong N/A C

Highly

N/A

C useful to have a continuous coloured density spectrogram of the EEG and to be able to change the parameters of the spectrogram such as the power scale.

\section{- We recommend that Burst}

Suppression should be avoided in all circumstances unless to control high intracranial pressure.
- We recommend that if Burst Suppression is used the Suppression Ratio should be kept $<5 \%$.

\section{Assessment of}

sedation

\section{Q 3.1 Are pEEG values different between patients at the same subjective level of sedation?}

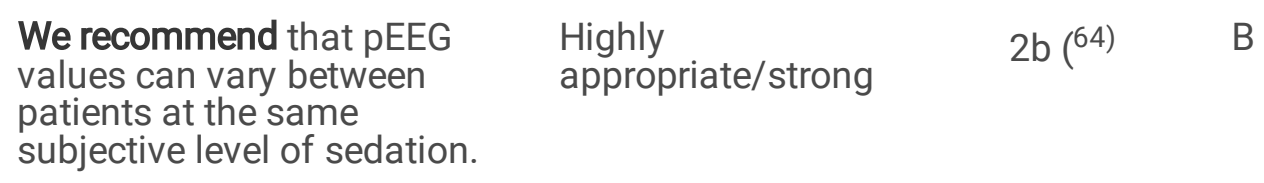

We recommend that $p E E G$ values can vary between patients at the same subjective level of sedation.

\section{Highly appropriate/strong} $2 b(64)$ B

Highly
appropriate/strong

$2 b(29,56)$

\section{Q 3.2 Are subjective} sedation scoring systems more reproducible than pEEG during light sedation, where electrical interference due to muscle activity may artificially elevate PEEG values?
We suggest that subjective sedation scoring systems are more reproducible than pEEG during light sedation, where electrical interference due to muscle activity may artificially elevate pEEG values.

$\begin{array}{lllll}\begin{array}{l}\text { Q 3.3 Should } \\ \text { measures of brain }\end{array} & \begin{array}{l}\text { We do not recommend the } \\ \text { use of instrumental }\end{array} & \begin{array}{l}\text { Unclear } \\ \text { appropriateness/weak }\end{array} & 2 b & \text { (71) }\end{array}$

N/A 
function $P E E G$ (BIS, EEG, PSI, SE) be used as the primary method to monitor depth of sedation in non-comatose, nonparalyzed critically ill adult patients?

Q 3.4 Are
measures of brain
function (pEEG)
adequate
substitutes for
subjective
sedation scoring
systems?

Q 3.5 Should measures of brain function (pEEG) be used as the main form of sedation assessments in adult ICU patients who are receiving NMBA, as subjective sedation assessments are unobtainable in these patients? monitoring to assess depth

of sedation in noncomatose/non-paralyzed patients.
We cannot recommend that measures of brain function (e.g., BIS, PSI, SE) are adequate substitutes for clinical scales (e.g., RASS and SAS)
Unclear appropriateness/no consensus
N/A

C

\section{Competences,}

training and support

Q 4.1 Is the pEEG
important enough
to need an official
structured
teaching and
training?

We recommend that when clinical scales (e.g. RASS and SAS) cannot be used such in adult ICU patients who are receiving NMBA, the use of brain function electronic tools and processed values should be mandatory.

\section{Highly \\ appropriate/strong}

$2 b^{(32)}$

B

\section{Q4.2 Is it necessary and preferable to dispatch a more holistic training with teaching of the theoretical, the neurological and/or pharmacological and the practical aspects of the \\ PEEG?}

We recommend a defined, structured teaching and training programme for pEEG monitoring.
Highly

appropriate/strong
N/A

C
While we suggest that training in pEEG monitoring could be delivered entirely in the clinical setting, we recommend that such training be framed by a holistic programme including theoretical and practical aspects, whether neurological or pharmacological.

a- Exclusive experiencebased education.

b- Holistic training of the pEEG. 


\section{pEEG monitoring training be considered similarly to the previous approach regarding different special techniques of monitoring or diagnosis as the transthoracic and/or trans- oesophageal echocardiography, others?}

\section{Q4.5 Would the} faculty include neuro-specialist (neurologist, epilepsy specialist...) regarding not only basic but also advanced theoretical aspects of the EEG and for that, will new learning resources need to be developed specifically to support training for the PEEG monitoring in the ICU? approaches applied to the training of other techniques introduced into anaesthesia and resuscitation practice (particularly ultrasoundbased echocardiography), to try to develop a learning and training programme specifically dedicated to pEEG.

\section{We recommend the}

participation, at least in an advisory capacity, of neurospecialists, to ensure the quality and relevance of the teaching. Furthermore, we recommend the development of new specific learning resources that embrace modern and interactive teaching methods.
Highly

appropriate/strong
N/A

C
Q 4.6 Has support to be available round the clock for the intensivist certified in PEEG monitoring?
In the current context of the development of interactivity and interdisciplinarity in medical practice, we recommend the implementation of round the clock systems of support for the intensivist certified in pEEG monitoring. However, we recognize the generic and centre-specific challenges imposed by such a recommendation.

\section{Q 4.7 Would support be required regarding technical issues or complex clinical issues or both?}

In a support system for the intensivist certified in $\mathrm{pEEG}$ monitoring we recommend to include support for complex clinical issues and suggest support for technical issues also.
Highly appropriate/strong
N/A

C

a- Complex clinical issues.

b- Technical issues

We recommend, as is the case for any medical
1. Highly appropriate/strong

2. Appropriate/strong
N/A C intensivist 


$\begin{array}{ll}\text { certified in pEEG } & \text { technology that is subject to } \\ \text { monitoring } & \text { change not only in its uses } \\ \text { demonstrate } & \text { but also in the information it } \\ \text { regular continuing } & \text { provides, continuous } \\ \text { professional } & \text { professional development } \\ \text { development } & \text { activities relevant to pEEG } \\ \text { activities relevant } & \text { monitoring. } \\ \text { to pEEG } & \\ \text { monitoring? } & \end{array}$

Q 4.9 Does the We recommend regular

intensivist

certified in pEEG

monitoring require

regular

recertification in

pEEG monitoring

and regarding its

theme, should it

be based on

review of cases

that demonstrate

required

competencies or

on a written

examination or

both? recertification of the

intensivist certified in pEEG

monitoring is required and

that this is primarily based

on review of cases that

demonstrate required

competencies. We

suggest that the review of

cases might be

supplemented by a written

examination.

a- Regular certification

b- Review of cases

demonstrating required

competencies

c- Written examination

d- Both, review of cases \& written examination.

\section{Figures}




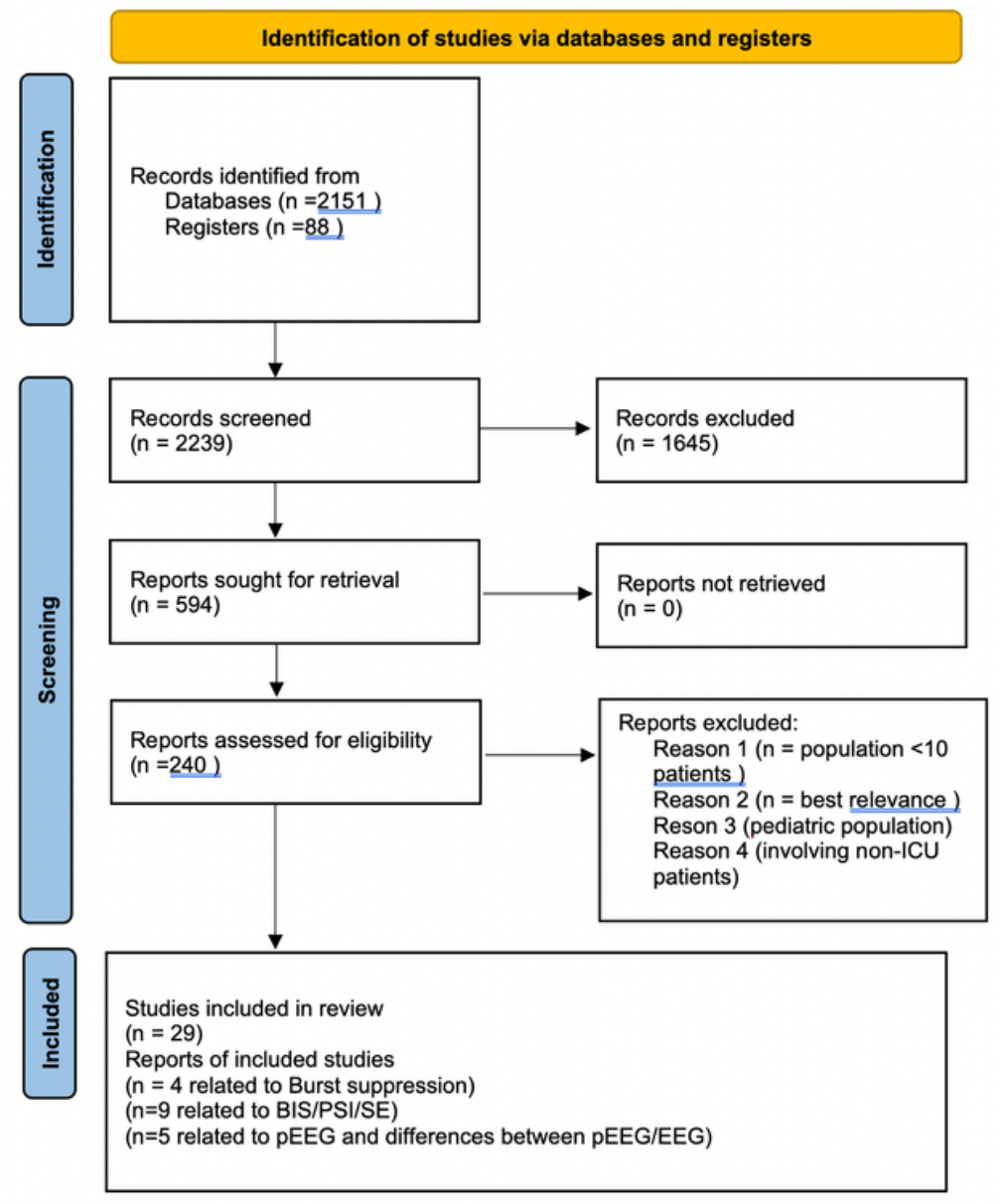

Records identified from:

Websites $(n=0)$

Organisations $(n=0)$

Citation searching $(n=0)$

etc.

Figure 1. PRISMA 2020 flow diagram for new systematic reviews including searches of databases, registers and other sources

\section{Figure 1}

See image above for figure legend

\section{Supplementary Files}

This is a list of supplementary files associated with this preprint. Click to download.

- Additionalfile1searchstrategy.docx

- Additionalfile2.RoB.docx

- Additionalfile3GRADEpEEGConsensuspaper.docx

- Additionalfile4Definitions.docx 